\title{
A Coupled Decadal Prediction of the Dynamic State of the Kuroshio Extension System
}

\author{
Bo QIU, SHuiming CHEN, AND NikLAs SCHNEIDER \\ Department of Oceanography, University of Hawai'i at Mānoa, Honolulu, Hawaii \\ BUNMEI TAGUCHI \\ Earth Simulator Center, JAMSTEC, Yokohama, Japan
}

(Manuscript received 29 May 2013, in final form 18 October 2013)

\begin{abstract}
Being the extension of a wind-driven western boundary current, the Kuroshio Extension (KE) has long been recognized as a turbulent current system rich in large-amplitude meanders and energetic pinched-off eddies. An important feature emerging from recent satellite altimeter measurements and eddy-resolving ocean model simulations is that the KE system exhibits well-defined decadal modulations between a stable and an unstable dynamic state. Here the authors show that the decadally modulating KE dynamic state can be effectively defined by the sea surface height (SSH) anomalies in the $31^{\circ}-36^{\circ} \mathrm{N}, 140^{\circ}-165^{\circ} \mathrm{E}$ region. By utilizing the SSH-based KE index from 1977 to 2012, they demonstrate that the time-varying KE dynamic state can be predicted at lead times of up to $\sim 6 \mathrm{yr}$. This long-term predictability rests on two dynamic processes: 1) the oceanic adjustment is via baroclinic Rossby waves that carry interior wind-forced anomalies westward into the $\mathrm{KE}$ region and 2) the low-frequency KE variability influences the extratropical storm tracks and surface wind stress curl field across the North Pacific basin. By shifting poleward (equatorward) the storm tracks and the large-scale wind stress curl pattern during its stable (unstable) dynamic state, the KE variability induces a delayed negative feedback that can enhance the predictable SSH variance on the decadal time scales.
\end{abstract}

\section{Introduction}

The Kuroshio Extension (KE) is an eastward-flowing, inertial jet in the subtropical western North Pacific Ocean after the Kuroshio separates from the coast of Japan. Being the extension of a wind-driven western boundary current, the KE has long been recognized as a turbulent current system rich in large-amplitude meanders and energetic pinched-off eddies (e.g., Mizuno and White 1983; Qiu and Chen 2005; Kelly et al. 2010). Not only is it a region abundant with oceanic mesoscale variability, the KE region is also where the largest interannual and longer time scale ocean circulation changes are detected in the North Pacific Ocean (Fig. 1a).

A significant advancement has been made over the last decade regarding the phenomenology and the dynamic causes for the low-frequency KE changes based on satellite altimeter measurements and eddy-resolving

Corresponding author address: Dr. Bo Qiu, Department of Oceanography, University of Hawai`i at Mānoa, 1000 Pope Road, Honolulu, HI 96822.

E-mail: bo@soest.hawaii.edu ocean general circulation models (OGCMs). It is by now well established that the KE system exhibits clearly defined decadal modulations between a stable and an unstable dynamic state (e.g., Qiu and Chen 2005, 2010; Taguchi et al. 2007, 2010; Kelly et al. 2007; Ceballos et al. 2009). When in its stable dynamic state, the KE jet tends to have an intensified eastward transport, a northward latitudinal position, an enhanced southern recirculation gyre, and a decreased regional eddy kinetic energy level. The reverse is true when the KE jet switches to an unstable dynamic state.

What is responsible for the transitions between the stable and unstable states of the KE system has been explored extensively both observationally and based on ocean circulation models of various complexities (Miller et al. 1998; Seager et al. 2001; Schneider et al. 2002; Qiu 2003; Taguchi et al. 2007; Sasaki et al. 2013). The consensus reached by these studies is that the transitions are controlled by the decadally fluctuating wind stress curl forcing over the central midlatitude North Pacific Ocean. Specifically, when the central North Pacific wind stress curl anomalies are positive, enhanced Ekman flux divergence generates negative local sea surface height (SSH) 

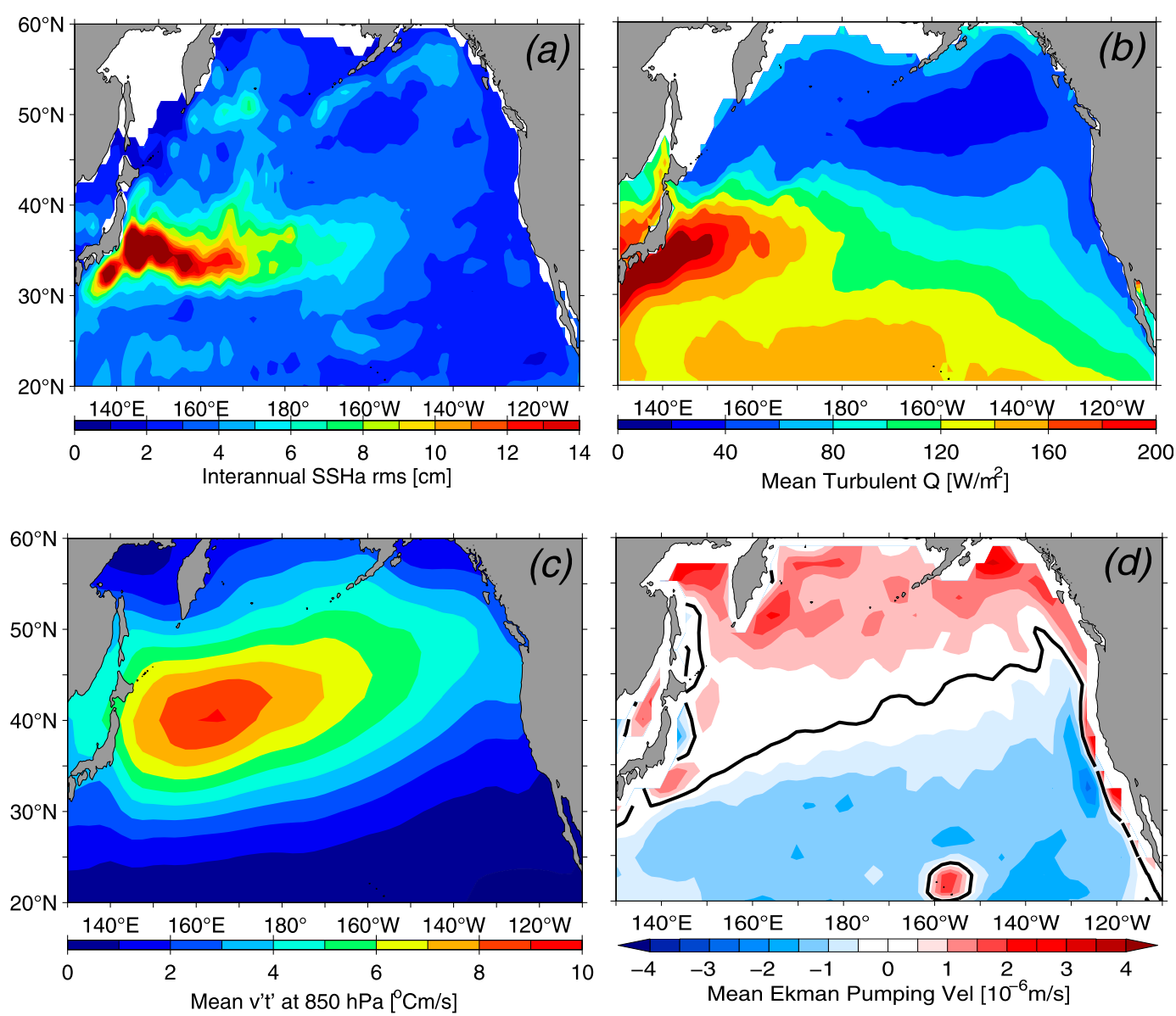

FIG. 1. (a) Root-mean-square amplitude of the low-pass filtered Archiving, Validation, and Interpretation of Satellite Oceanographic data (AVISO) SSH signals from October 1992 to December 2012. The low-pass filter has a half-power at 2 yr. (b) Climatological mean surface turbulent heat flux map from the OAFlux product (positive upward). (c) Climatological mean transient eddy temperature flux $\overline{v^{\prime} T^{\prime}}$ map. Here, $\overline{v^{\prime} T^{\prime}}$ are based on the $2-8$-day bandpass-filtered NCEP-NCAR reanalysis temperature and velocity data at the 850-hPa level. (d) Climatological mean Ekman pumping velocity map based on the NCEP-NCAR reanalysis wind stress data. Thick black contours denote $w_{\mathrm{Ek}}=0$.

anomalies. As these wind-induced negative SSH anomalies propagate westward into the $\mathrm{KE}$ region after a delay of 3-4 yr, they weaken the zonal KE jet, leading to an unstable state of the KE system with a reduced recirculation gyre and an active eddy kinetic energy field. The negative, anomalous wind stress curl forcing in the central North Pacific, on the other hand, generates positive SSH anomalies through the Ekman flux convergence. After propagating into the $\mathrm{KE}$ region in the west, these anomalies stabilize the KE system by increasing the KE transport and shifting its position northward.

The decadally modulating KE dynamic state brings about significant changes in the regional sea surface temperature, upper-ocean heat content, and water mass properties of subtropical mode water, central mode water, and North Pacific Intermediate Water (Qiu 2000;
Vivier et al. 2002; Qiu and Chen 2006, 2011; Oka et al. 2012). For example, the elevated eddy variability during the KE unstable state brings upper-ocean high potential vorticity water of the mixed water region southward, creating a stratified upper-ocean condition in the southern recirculation gyre region unfavorable for the wintertime deep convection and subtropical mode water formation. By affecting the regional thermal conditions and mesoscale eddy activities, the decadal KE variability has also been found to exert a great influence on marine ecosystems and fisheries in the western North Pacific Ocean (e.g., Noto and Yasuda 1999; Miller et al. 2004; Nishikawa et al. 2011).

With such broad impacts, it is natural to inquire if the dynamic state of the KE system can be predicted into the future. Given the delayed adjustment by the KE jet in 
response to the surface wind stress forcing, the westward propagation process has been exploited in the past in predicting the wintertime sea surface temperature (SST) anomalies north of the KE jet by Schneider and Miller (2001) and the KE jet speed by Nonaka et al. (2012). Note that, in these "one way" prediction studies, the predicted KE dynamic state is determined entirely by the adopted ocean model dynamics and has no dependency on future wind variability.

The objective of our current study is to explore the extent to which we may extend the prediction of the KE dynamic state by taking into account the oceanatmosphere coupling between the KE and overlying atmosphere. By transporting warmer tropical water poleward to the midlatitude North Pacific, the KE provides a significant source of heat and moisture for the overlying atmosphere (Fig. 1b). This source of oceanic origin has been demonstrated by several recent studies to help maintain the lower tropospheric baroclinicity and anchor the extratropical storm tracks (Fig. 1c) (Hoskins and Valdes 1990; Nakamura et al. 2004; Minobe et al. 2008; Joyce et al. 2009; Tokinaga et al. 2009; Taguchi et al. 2009; Kwon et al. 2010). Many data analysis studies in the past decade have examined the impact of the SST changes in the KE region upon the atmospheric circulation changes over the North Pacific basin (e.g., Wu et al. 2003; Frankignoul and Sennéchael 2007; Qiu et al. 2007; Frankignoul et al. 2011; Taguchi et al. 2012; Kwon and Joyce 2013). Although the KE feedback-induced atmospheric changes are weak in comparison with the internal atmospheric fluctuations (typically at $10 \%-15 \%$ level for the interannual and decadal signals), coupled general circulation model simulations have shown that the midlatitude air-sea coupling can enhance the decadal climate variability in the North Pacific (e.g., Latif and Barnett 1994; Pierce et al. 2001; Kwon and Deser 2007). Indeed, we will demonstrate in this study that taking into account the forcing by the KE feedback-induced surface wind anomalies can improve the long-term prediction of the dynamic state of the KE system.

The paper is organized as follows. After describing the observational data and the high-resolution OGCM product in section 2, we examine in section 3 the KE variability on decadal time scales and introduce an index that comprehensively captures the decadally fluctuating $\mathrm{KE}$ system. Section 4 explores how changes in the KE dynamic state affect the broad-scale surface ocean and atmosphere signals: SST, surface turbulent heat fluxes, storm track activity, and Ekman pumping velocities. Relevance of this air-sea feedback upon the prediction of the KE index is quantified in section 5. Section 6 summarizes the outcome from the present study.

\section{Observational data and the OFES model output}

To examine the changes in the KE dynamic state, we use the global SSH anomaly dataset compiled by the Collocte Localisation Satellites (CLS) Space Oceanographic Division of Toulouse, France. This dataset merges along-track SSH measurements from all satellite altimeter missions after October 1992 and has a 7-day temporal resolution and a $1 / 3^{\circ}$ longitude Mercator spatial resolution (Ducet et al. 2000). The data period analyzed in this study extends from October 1992 to December 2012. From the SSH anomaly field $h^{\prime}(x, y, t)$, the absolute SSH field is obtained by adding the mean SSH data derived by Teague et al. (1990) to the $h^{\prime}(x, y, t)$ field.

To extend the KE index time series prior to the satellite altimeter period, we utilize the output from the multidecadal hindcast run of the OGCM for the Earth Simulator (OFES). Covering the global domain from $75^{\circ} \mathrm{S}$ to $75^{\circ} \mathrm{N}$, the OFES model has an eddyresolving $0.1^{\circ} \times 0.1^{\circ}$ horizontal grid resolution and 54 vertical levels. The model code is based on Modular Ocean Model, version 3 (MOM3), modified for optimal performance by the Earth Simulator of Japan (Sasaki et al. 2008). The model was spun up for 50 years with monthly climatological atmospheric forcing from the National Centers for Environmental PredictionNational Center for Atmospheric Research (NCEPNCAR) reanalysis (Kistler et al. 2001). This climatological run was followed by a 63-yr hindcast integration for the period of 1950-2012 using the NCEP-NCAR reanalysis daily-mean forcing data. In the present study, the model output from the 63-yr hindcast run is analyzed.

To relate the KE variability to those at the air-sea interface and in the overlying atmosphere, we use the monthly SST and surface turbulent (sensible and latent) heat flux data of the objectively analyzed air-sea fluxes (OAFlux) product by $\mathrm{Yu}$ and Weller (2007) and the daily atmospheric wind and temperature data from the NCEP-NCAR reanalysis by Kistler et al. (2001). The OAFlux datasets have $1^{\circ}$ spatial resolution and are available from 1958 to 2012, and the NCEP-NCAR reanalysis dataset has a spatial resolution of $1.9^{\circ}$ latitude $\times 1.875^{\circ}$ longitude and spans the period of 1948 2012. To infer the storm track activities, we follow Nakamura et al. (2002) and calculate synoptic-scale (2-8 days) transient eddy temperature fluxes by using the daily wind and temperature data at the $850-\mathrm{hPa}$ geopotential height from the NCEP-NCAR reanalysis. For all sea surface and atmospheric variables, we derive their monthly anomaly time series by removing the climatological monthly values. 

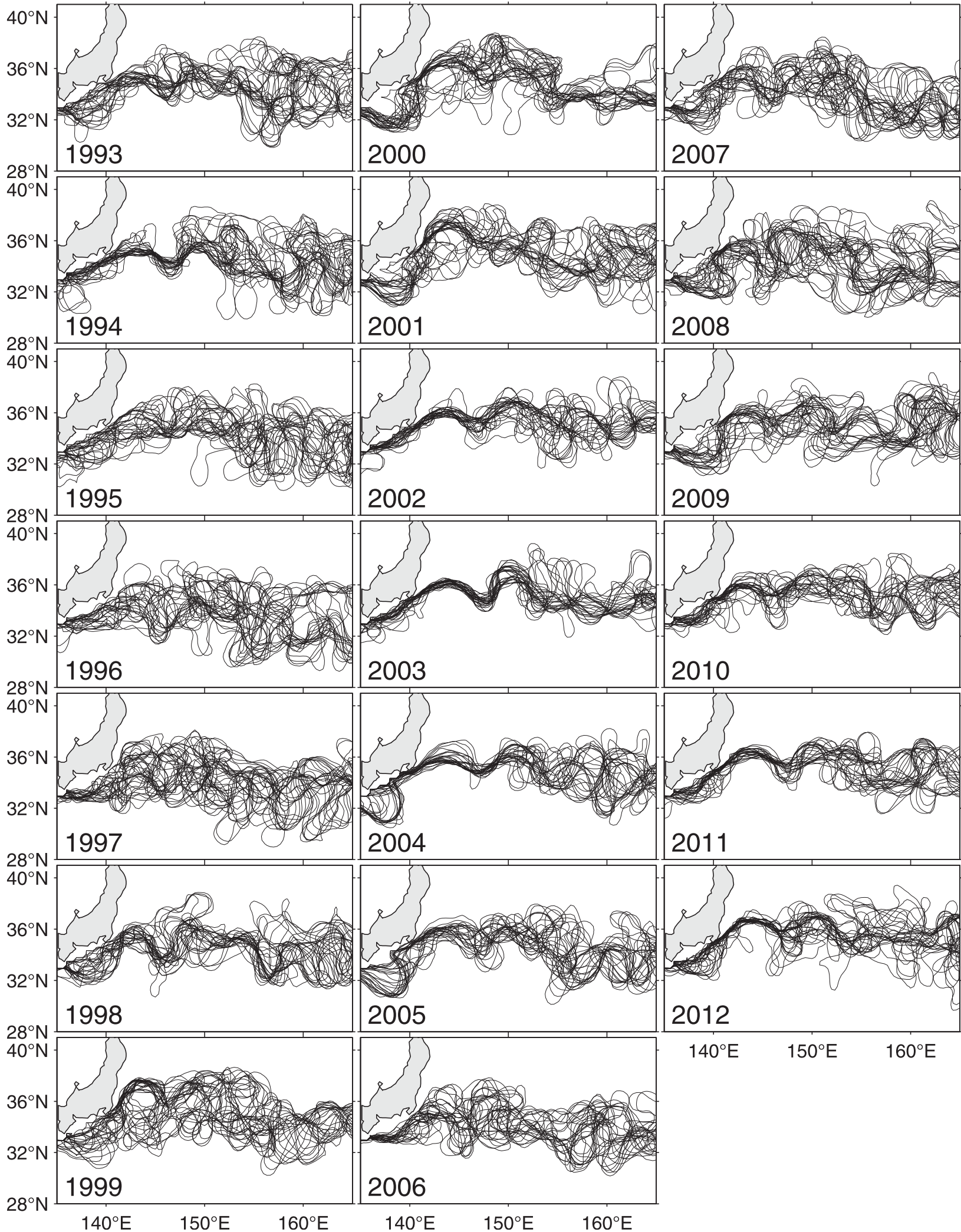

$140^{\circ} \mathrm{E} \quad 150^{\circ} \mathrm{E} \quad 160^{\circ} \mathrm{E}$

FIG. 2. Yearly paths of the Kuroshio and Kuroshio Extension defined by the $170-\mathrm{cm}$ contours in the weekly SSH fields from the satellite altimeter measurements: paths at every 14 days are plotted. 


\section{Decadal KE variability and its index}

As noted in the introduction, the KE system has been detected in several recent studies to oscillate between a stable and an unstable dynamic state. In this section, we will update the dynamic state of the decadally varying KE system based on the satellite altimeter observations and provide rationales for constructing an index that succinctly represents the low-frequency variations of the KE system.

A visual way to describe the decadal KE jet variability is to superimpose snapshots of the KE paths in individual years (Fig. 2). Here, the KE paths are defined by the $170-\mathrm{cm} \mathrm{SSH}$ contours in the weekly absolute SSH maps from the satellite altimeter measurements [for more details see Qiu and Chen (2005)]. In the period of the past two decades, the KE paths were relatively stable in 1993-95, 2002-05, and 2010-12 and spatially convoluted paths prevailed in 1996-2001 and 2006-09. These visual changes in the KE path stability can be quantified by evaluating the length of the KE path integrated from $140^{\circ}$ to $153^{\circ} \mathrm{E}$. As shown in Fig. 3a, the KE jet is in a stable dynamic state, if the pathlength is short, and a longer pathlength signifies an unstable dynamic state. Notice that the variability in its path stability constitutes merely one aspect of the decadally modulating KE system. When the KE jet is in a stable dynamic state, satellite altimeter measurements further reveal that its eastward surface transport tends to increase (Fig. 3b), its latitudinal position tends to migrate northward (Fig. 3c), and its southern recirculation gyre tends to strengthen (Fig. 3d). The reverse is true when the KE jet switches to an unstable dynamic state. Notice that the terminology "stable" versus "unstable" is used in this study to indicate the dynamic state of the KE system; it is not in reference to the necessary condition for instability of the KE jet.

Given the correlation among these dynamic properties of the KE system, it is useful for prediction purposes to introduce a single time series that can reflect the KE's time-varying dynamic state comprehensively. In this study, we define the KE index by averaging the anomalies of the four time series shown in Figs. 3a-d (with the sign for the KE pathlength in Fig. 3a reversed) normalized by their respective standard deviations. The gray line in Fig. 4a shows the weekly KE index thus constructed and the black line shows the low-pass filtered KE index after removal of signals shorter than the annual period. By definition, a positive KE index signifies a stable dynamic state in which the KE jet has a steady and northerly path, an increased surface transport, and an enhanced southern recirculation gyre. An unstable dynamic state with the opposite properties is denoted by a negative $\mathrm{KE}$ index.

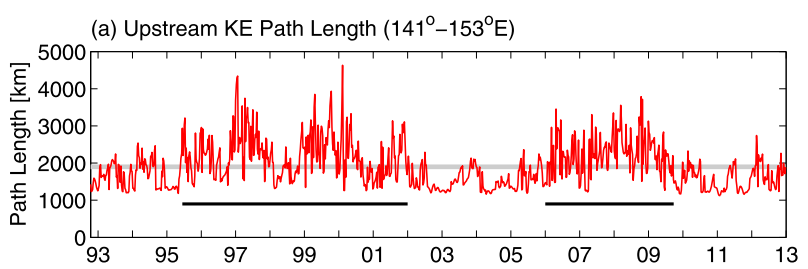

(b) KE Strength $\left(140^{\circ}-165^{\circ} \mathrm{E}\right)$

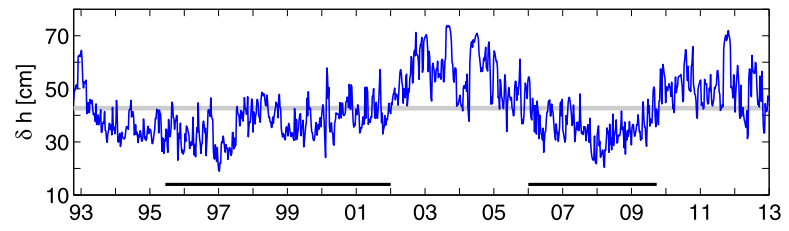

(c) Upstream KE Position $\left(141^{\circ}-158^{\circ} \mathrm{E}\right)$

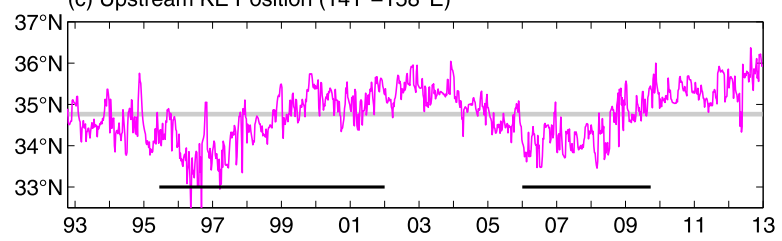

(d) KE Recirculation Gyre Strength

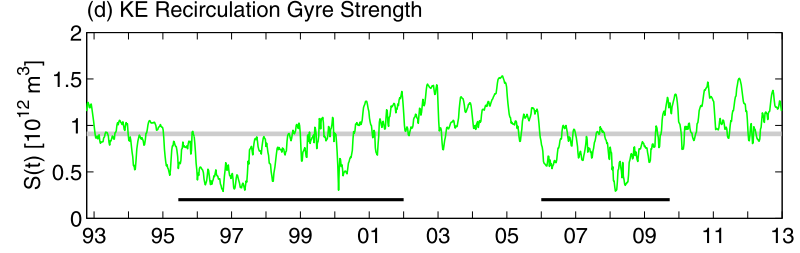

FIG. 3. Time series of (a) upstream KE pathlength integrated from $140^{\circ}$ to $153^{\circ} \mathrm{E}$, (b) SSH difference across the KE jet averaged from $140^{\circ}$ to $165^{\circ} \mathrm{E}$, (c) latitudinal position of the KE averaged from $141^{\circ}$ to $158^{\circ} \mathrm{E}$, and (d) intensity of the KE recirculation gyre based on the satellite altimeter measurements. Gray lines denote the mean values averaged over the period of analysis. Thick black lines denote the periods when the KE is in an unstable dynamic state.

A regression analysis between the KE index and the SSH anomaly time series in the North Pacific Ocean reveals that the KE index constructed from its four dynamic properties can be favorably represented by the SSH anomaly signals in the $31^{\circ}-36^{\circ} \mathrm{N}, 140^{\circ}-165^{\circ} \mathrm{E}$ region (Fig. 4c). Indeed, the linear correlation coefficient between the low-pass filtered SSH anomaly time series averaged in $31^{\circ}-36^{\circ} \mathrm{N}, 140^{\circ}-165^{\circ} \mathrm{E}$ (Fig. $4 \mathrm{~b}$ ) and the lowpass filtered KE index in Fig. 4a is as high as $r=0.96$. (Like Fig. 4a, the low-pass filter used in Fig. 4b removes the SSH signals shorter than the annual period; $r=0.84$ between the original weekly time series.) Notice that the $31^{\circ}-36^{\circ} \mathrm{N}, 140^{\circ}-165^{\circ} \mathrm{E}$ region is geographically occupied by the time-mean KE jet and its southern recirculation gyre. With the KE being the inertial western boundary current jet of the subtropical gyre whose variability is closely tied to its southern recirculation gyre, it makes 
(a) Synthesized KE Index

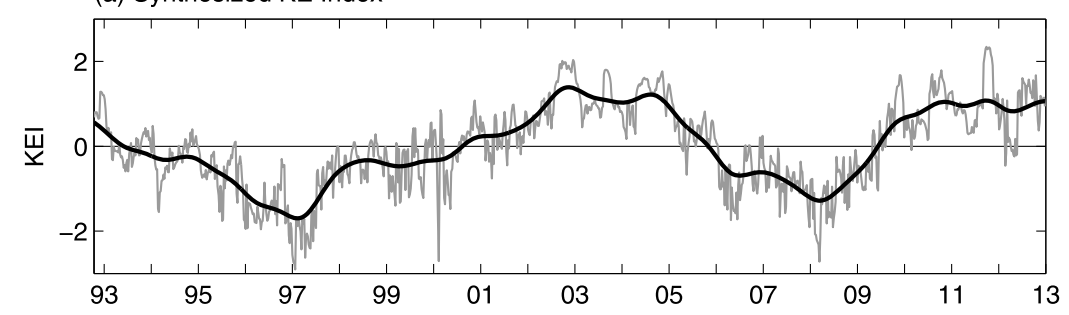

(b) SSHa in $140-165^{\circ} \mathrm{E}, 31-36^{\circ} \mathrm{N}$

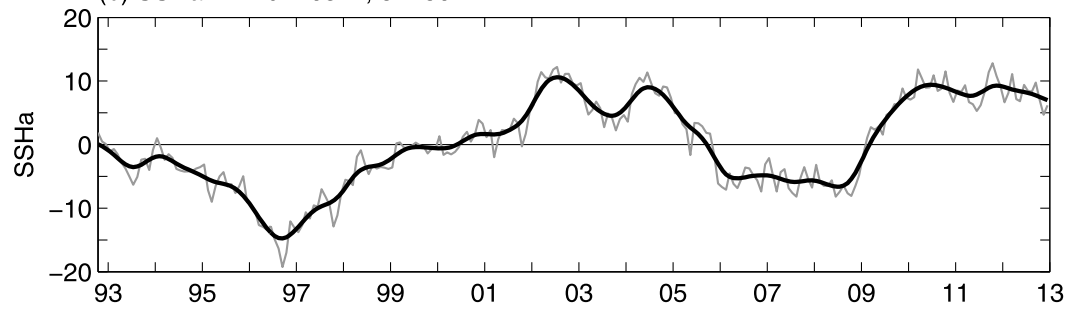

(c) Regression Coefficient

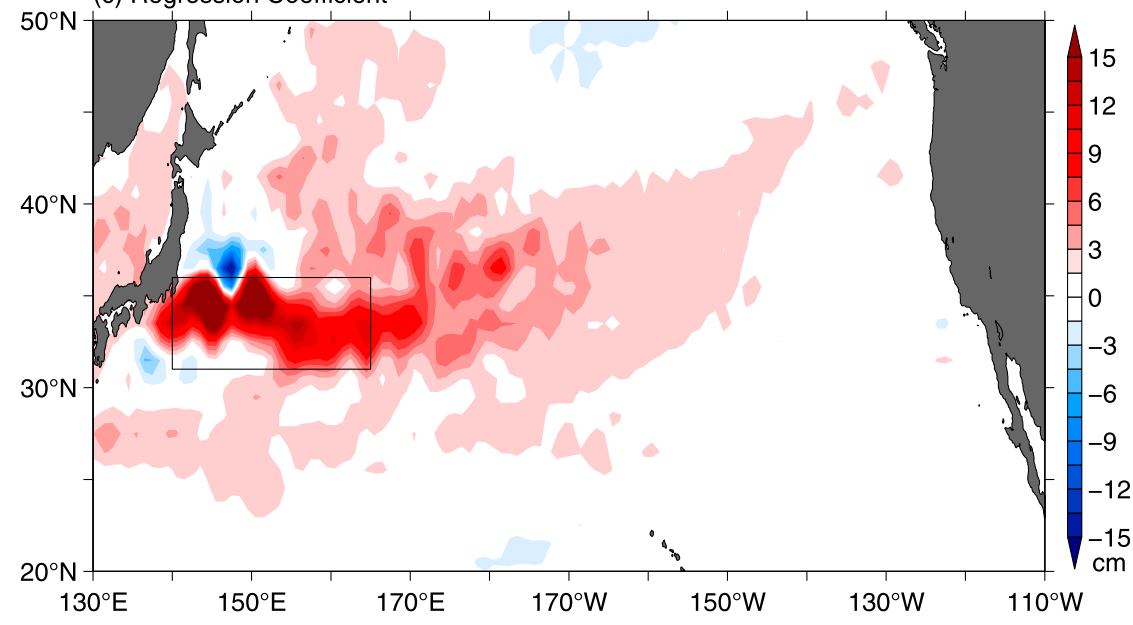

FIG. 4. (a) KE index time series synthesized from the four dynamic quantities shown in Fig. 3. (b) Time series of the $\mathrm{SSH}$ anomalies averaged in the region $31^{\circ}-36^{\circ} \mathrm{N}, 140^{\circ}-165^{\circ} \mathrm{E}$ [i.e., the rectangular box in (c)]. In both (a) and (b) gray and dark lines denote the weekly and low-pass filtered values, respectively. (c) Regression map between the KE index shown in (a) and the SSH anomaly time series in the North Pacific Ocean. All results are based on the satellite altimeter measurements.

physical sense that its time-varying dynamic state can be represented by the SSH signals in this key region.

This result of high correlation presented in Fig. 4 is important in two respects. First, it indicates that predicting the time-varying dynamic state of the KE system is equivalent to predicting anomalous SSH signals in the $31^{\circ}-36^{\circ} \mathrm{N}$, $140^{\circ}-165^{\circ} \mathrm{E}$ region that encompasses the $\mathrm{KE}$ jet and its southern recirculation gyre. As the large-scale $\mathrm{SSH}$ changes in midlatitude oceans are controlled by the linear baroclinic vorticity dynamics (see Qiu 2002, and references therein), this provides us with a dynamic framework to explore the $\mathrm{KE}$ index prediction. Second, while formulating the KE index of Fig. 4a based on the four dynamic properties can be labor intensive, constructing the proxy KE index of Fig. $4 \mathrm{~b}$ using the regional SSH signals is simple and straightforward. For these two reasons, we will focus hereafter in this study on the KE index based on the SSH anomalies in $31^{\circ}-36^{\circ} \mathrm{N}, 140^{\circ}-165^{\circ} \mathrm{E}$.

To enhance the statistical confidence in exploration of predictability, it is essential to extend the time series of the KE index for as long a period as possible. To achieve this, we utilize the multidecadal OFES hindcast run output and plot in Fig. 5a the modeled SSH anomaly time series averaged in the key region of $31^{\circ}-36^{\circ} \mathrm{N}, 140^{\circ}-165^{\circ} \mathrm{E}$. Compared to the observed SSH signals shown in Fig. 4b, the two time series have a linear correlation coefficient $r=0.81$ for the overlapping period of 1992-2012. This favorable comparison indicates that the OFES hindcast captured well the decadally modulating KE system, a result consistent with the findings of other recent 

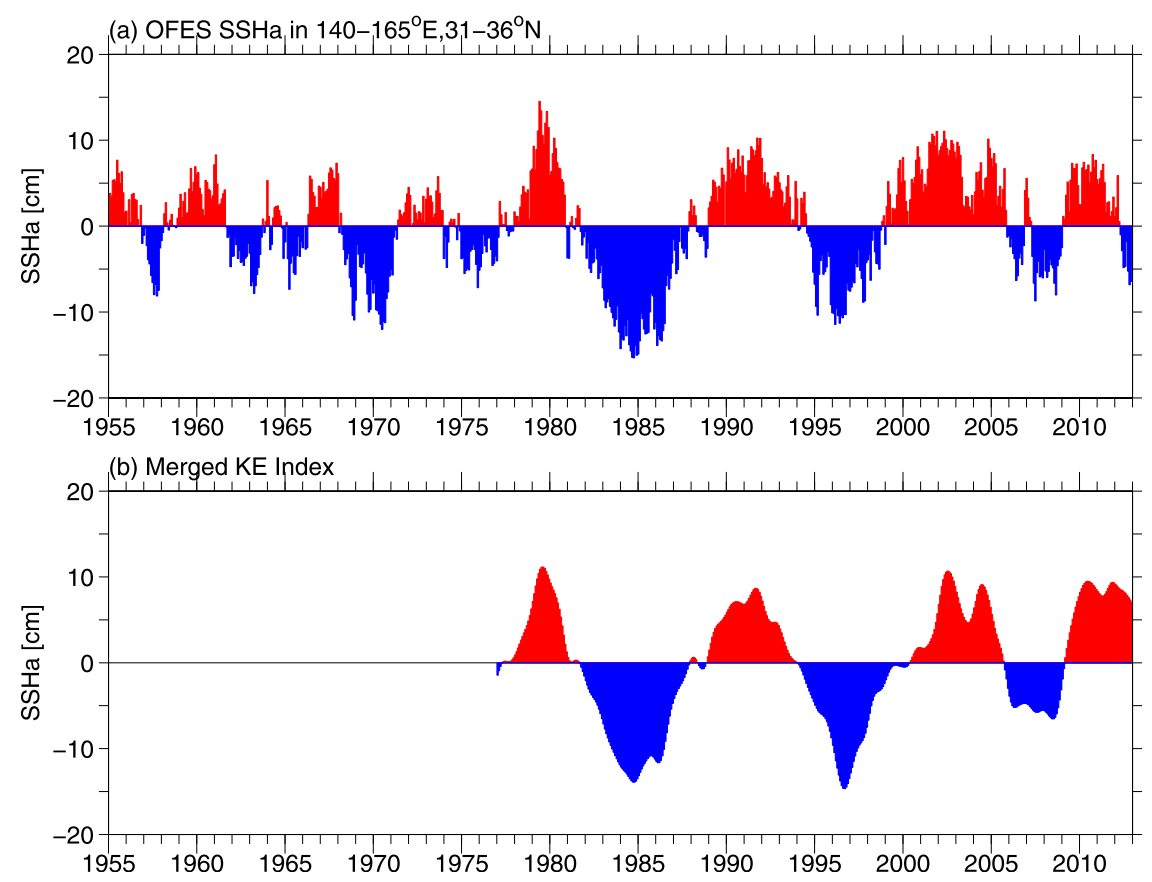

FIG. 5. (a) Monthly KE index based on the OFES SSH anomaly data averaged within $31^{\circ}-36^{\circ} \mathrm{N}, 140^{\circ}-165^{\circ} \mathrm{E}$. (b) Low-pass filtered $\mathrm{KE}$ index after the $1976-77$ climate shift that merges the satellite altimeter data of 1992-2012 (i.e., Fig. 4b) and the OFES result of 1977-92.

studies analyzing the OFES hindcast output (Nonaka et al. 2006; Taguchi et al. 2007; Ceballos et al. 2009; Sasaki et al. 2013).

From Fig. 5a, it is clear that the decadal KE modulations similar to those detected in the recent two decades have persisted following the 1976-77 regime shift in the North Pacific climate system (e.g., Trenberth and Hurrell 1994; Mantua et al. 1997). Prior to 1976-77, the KE index inferred from the OFES output exhibited shorter and less regular fluctuations, and the SSH anomalies in the KE region were not well connected to those in the central North Pacific basin (figure not shown). In our following examinations, we lengthen the observed KE index time series of Fig. $4 \mathrm{~b}$ by appending the OFES result before September 1992 and will focus on the prediction of the interannual KE index signals after the 1976-77 regime shift. In other words, the monthly "merged" KE index shown in Fig. $5 \mathrm{~b}$ will serve as the predictand in the following analyses.

\section{Atmospheric response to the decadal KE variability}

Given that the goal of this study is to examine the importance of air-sea coupling in the prediction of the $\mathrm{KE}$ index, it is important to first quantify the influence of the decadal KE variability upon the physical variables at the air-sea interface and in the overlying atmosphere. Specifically, we will in this section focus on four variables: the turbulent surface heat flux, SST, lower tropospheric storm track activity, and Ekman pumping velocity. Although only the Ekman pumping velocity $w_{\text {Ek }}$ directly affects the KE index prediction (see section 5 below), examination of the other three variables helps to present a more coherent picture as to how the atmosphere responds to the KE variability across the broad North Pacific basin.

To evaluate the impact of the KE variability, we adopt the lagged correlation analysis approach proposed by Frankignoul et al. (1998). This approach has been applied by many investigators in their respective studies on the influence of the midlatitude SST variations upon the overlying atmosphere in the North Pacific basin (Wu et al. 2003; Frankignoul and Sennéchael 2007; Qiu et al. 2007; Frankignoul et al. 2011; Taguchi et al. 2012; Kwon and Joyce 2013). The essence of the Frankignoul et al. approach is to examine the covariability of an atmospheric variable (e.g., $w_{\mathrm{Ek}}$ ) and the KE index with a lag that is longer than the intrinsic atmospheric time scale ( $\sim 2$ months, Deser et al. 2007) but shorter than the persistence time scale of the KE index (estimated to be 40 months). By denoting the KE index as 

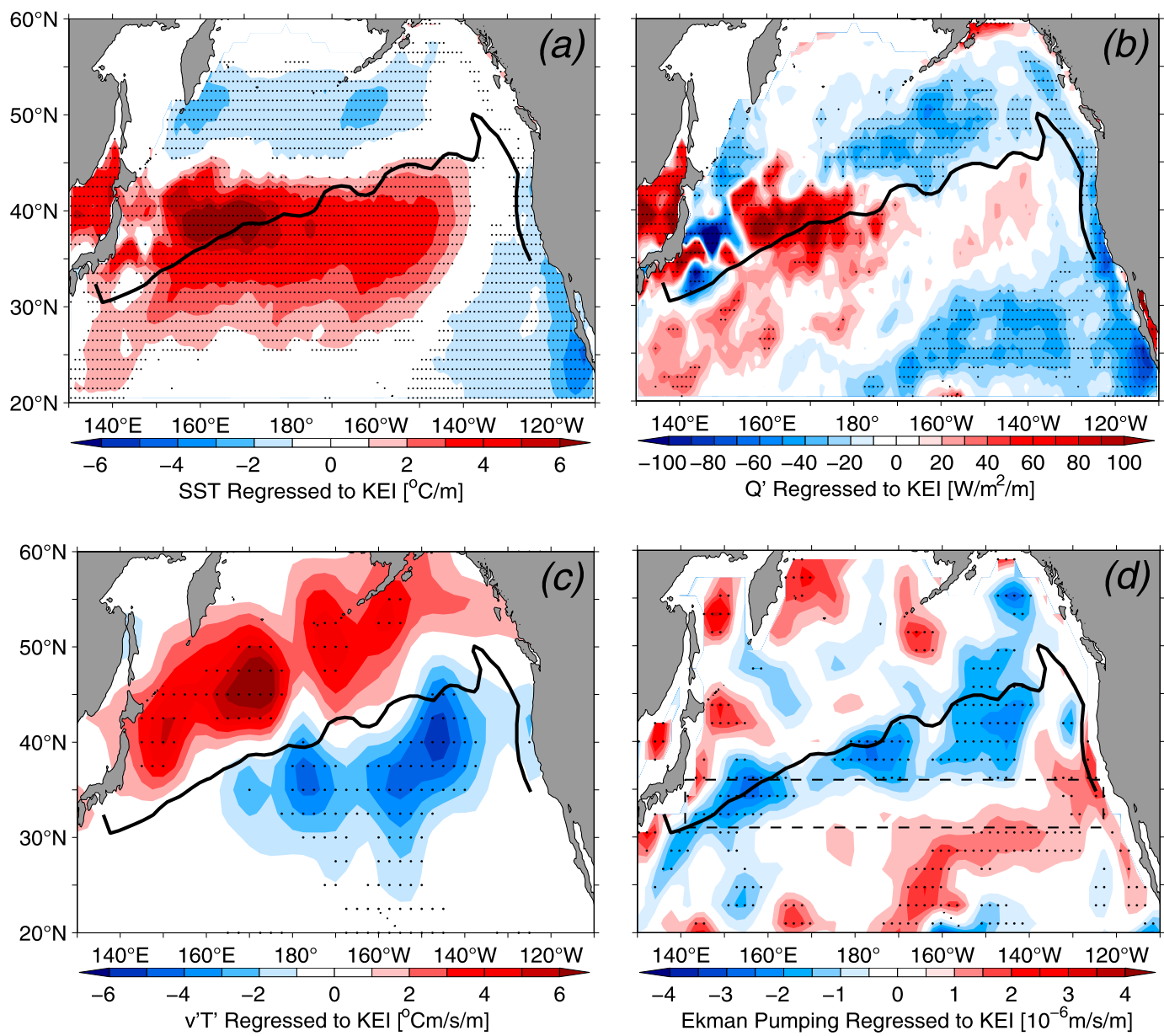

FIG. 6. (a) Regression coefficient between the SST anomaly field and the KE index of 1977-2012 with the former lagging the latter by 2 months. (b) As in (a), but for the surface turbulent heat flux anomaly field. (c) As in (a), but for the transient eddy temperature flux anomaly field. (d) As in (a), but for the Ekman pumping velocity anomaly field. In all figures, the black contour denotes the time-mean $w_{\mathrm{Ek}}=0$ line and stippled areas indicate where the statistical significance exceeds the $90 \%$ confidence level based on Monte Carlo simulations (for the detailed methodology, see Qiu et al. 2007). In (d) the dashed box indicates the $31^{\circ}-36^{\circ} \mathrm{N}$ band where the feedback Ekman pumping forcing impacts the KE index prediction.

$I_{\mathrm{KE}}(t)$ and the atmospheric variable as $A(x, y, t)$, the lagged regression coefficient

$$
b(x, y)=\frac{\left\langle I_{\mathrm{KE}}(t) A(x, y, t+m)\right\rangle}{\sqrt{\left\langle I_{\mathrm{KE}}^{2}(t)\right\rangle}},
$$

in this case, represents the spatial response of the atmospheric variable to the time-varying $\mathrm{KE}$ dynamic state. In (1) angle brackets denote the ensemble average over the 432 months of $1977-2012$ and the time lag is set at $m=2$ months. Before calculating $b(x, y)$, we follow the previous studies and remove by linear regression the Niño-3.4 SST anomaly signals from both the $I_{\mathrm{KE}}(t)$ and $A(x, y, t)$ time series in order to minimize the low-frequency signals teleconnected from the tropics (Alexander et al. 2002).
Figure 6a shows the $b(x, y)$ pattern for the SST anomalies. Positive anomalies appear within the broad $30^{\circ}-40^{\circ} \mathrm{N}$ band occupied by the KE and its eastward continuation, known as the North Pacific Current. Notice that the $b(x, y)$ pattern in Fig. 6a is similar to Fig. 4c, the SSH pattern regressed to the KE index. This similarity indicates that the warm SST anomalies in the $30^{\circ}-40^{\circ} \mathrm{N}$ band are controlled more by oceanic processes, that is, the strengthened KE jet and its poleward migration during the positive phase of the KE index, than by the surface heat flux forcing (Qiu 2000; Vivier et al. 2002; Kwon and Deser 2007). Indeed, the spatial pattern of the turbulent heat flux anomalies regressed to the KE index (Fig. 6b) reveals that the anomalous turbulent heat flux is mostly positive (defined in this study as from the ocean to the atmosphere) over the warm SST band. In other words, the warm SST anomalies in the 
$30^{\circ}-40^{\circ} \mathrm{N}$ band are damped by the air-sea turbulent heat fluxes, rather than driven by them.

It is worth emphasizing that the warm SST anomalies seen in Fig. 6a lie underneath the mean path of the North Pacific extratropical storm tracks (recall Fig. 1c). Here, we follow Nakamura et al. (2002) and have represented the storm-track activity signals by the 2-8-day bandpass-filtered poleward eddy temperature flux $\overline{v^{\prime} T^{\prime}}$ data at the $850-\mathrm{hPa}$ level from the NCEP-NCAR reanalysis data. Figure $6 \mathrm{c}$ shows the $b(x, y)$ pattern for the storm-track activity anomalies and it exhibits a clear dipolar pattern with a dividing line oriented northeastsouthwestward following the mean storm track path, or the mean $w_{\mathrm{Ek}}=0$ line (the thick black line in Fig. $6 \mathrm{c}$ ). This dipolar pattern implies a poleward (equatorward) migration of the storm tracks when the KE index becomes positive (negative). The results shown in Figs. 6a-c are consistent with the notion that the extratropical storm tracks are anchored and energized by an oceanic front and heat release (Nakamura et al. 2004; Taguchi et al. 2009). Specifically, in its positive state when the KE jet is intensified and migrated poleward, warm SST anomalies and ocean-to-atmosphere heat release tend to expand northward, bringing about a northward shift in the overlying storm tracks.

Accompanying the KE-induced northward shift of the storm tracks is the poleward migration of the largescale Ekman pumping velocity signals. Figure $6 d$, showing the spatial pattern of the $w_{\mathrm{Ek}}$ anomalies regressed to the KE index with a 2-month lag, reveals a band of negative Ekman pumping anomalies that follows roughly the time-mean $w_{\mathrm{Ek}}=0$ contour (thick solid line in Fig. 6d). South of these northeast-southwestaligned negative anomalies, there exists a paralleling band of positive Ekman pumping anomalies. Given that the time-mean $w_{\text {Ek }}$ field is tilted northeast-southwestward and has a sinusoidal spatial pattern (recall Fig. 1d), the alternately signed anomaly bands in Fig. $6 \mathrm{~d}$ reflect that the large-scale surface wind stresses tend to migrate northward when the KE index is in its positive phase.

Notice that, within the $31^{\circ}-36^{\circ} \mathrm{N}$ band relevant for the $\mathrm{KE}$ index prediction (dashed box in Fig. 6d), the $w_{\mathrm{Ek}}$ anomalies due to the oceanic feedback are positive (negative) in the eastern (western) basin. This feedback pattern of $w_{\mathrm{Ek}}$ is consistent with our previous study (Qiu et al. 2007) in which, instead of the KE index introduced in this study, we used the observed SST anomalies as an indicator for the KE variability. The tendency that a northward-migrated KE jet tends to excite positive $w_{\mathrm{Ek}}$ anomalies in the eastern basin of the North Pacific Ocean is similarly detected in a recent study by Frankignoul et al. (2011, see their Fig. 13c). As will be detailed in the next section, this Ekman pumping forcing due to the

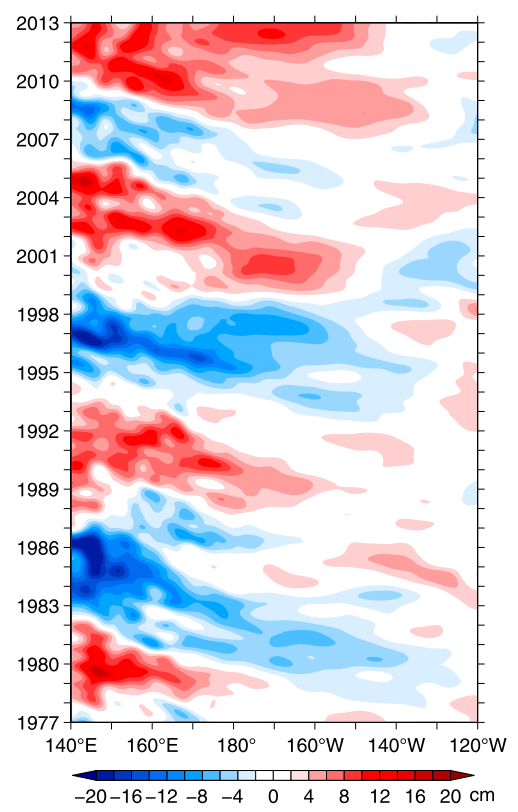

FIG. 7. Time-longitude plot of the low-pass filtered SSH anomalies along the $31^{\circ}-36^{\circ} \mathrm{N}$ band. Used for the initializations, these $\eta_{m}(x, t)$ data are merged from the satellite altimeter data of 1992-2012 and the OFES hindcast output of 1977-92. The $\eta_{m}(x, t)$ values averaged in the western $140^{\circ}-165^{\circ} \mathrm{E}$ segment form the KE index shown in Fig. $5 \mathrm{~b}$.

oceanic feedback is critical to the improved long-term prediction of the KE index.

\section{One-way versus two-way predictions}

The large-scale, wind-induced, $\mathrm{SSH}$ variability in a midlatitude ocean is governed by the long-wave linear vorticity equation:

$$
\frac{\partial \eta}{\partial t}-c_{R} \frac{\partial \eta}{\partial x}=-\frac{g^{\prime}}{g} w_{\mathrm{Ek}},
$$

where $\eta$ is the SSH anomaly of interest, $c_{R}$ the long baroclinic Rossby wave speed, $g$ the gravity constant, $g^{\prime}$ the reduced gravity, and $w_{\mathrm{Ek}}$ is the anomalous Ekman pumping velocity [for references and the underlying assumptions, see Qiu (2002)]. By solving Eq. (2) as an initial value problem, we can write the solution for $\eta$ as follows:

$$
\begin{aligned}
\eta(x, y, t)= & \eta\left[x+c_{R}\left(t-t_{o}\right), y, t_{o}\right] \\
& -\frac{g^{\prime}}{g} \int_{t_{o}}^{t} w_{E k}\left[x+c_{R}\left(t-t^{\prime}\right), y, t^{\prime}\right] d t^{\prime},
\end{aligned}
$$

where $t_{o}$ is the initialization time and $t>t_{o}$. As the KE index is constructed using the SSH anomalies in this study, Eq. (3) constitutes a useful dynamic framework to explore its predictability.

Adopting this framework, we initialize the SSH anomalies in the $31^{\circ}-36^{\circ} \mathrm{N}$ band by using the low-pass filtered SSH anomaly data, $\eta_{m}(x, t)$, merged from the satellite altimeter data and the OFES hindcast output (see Fig. 7). 


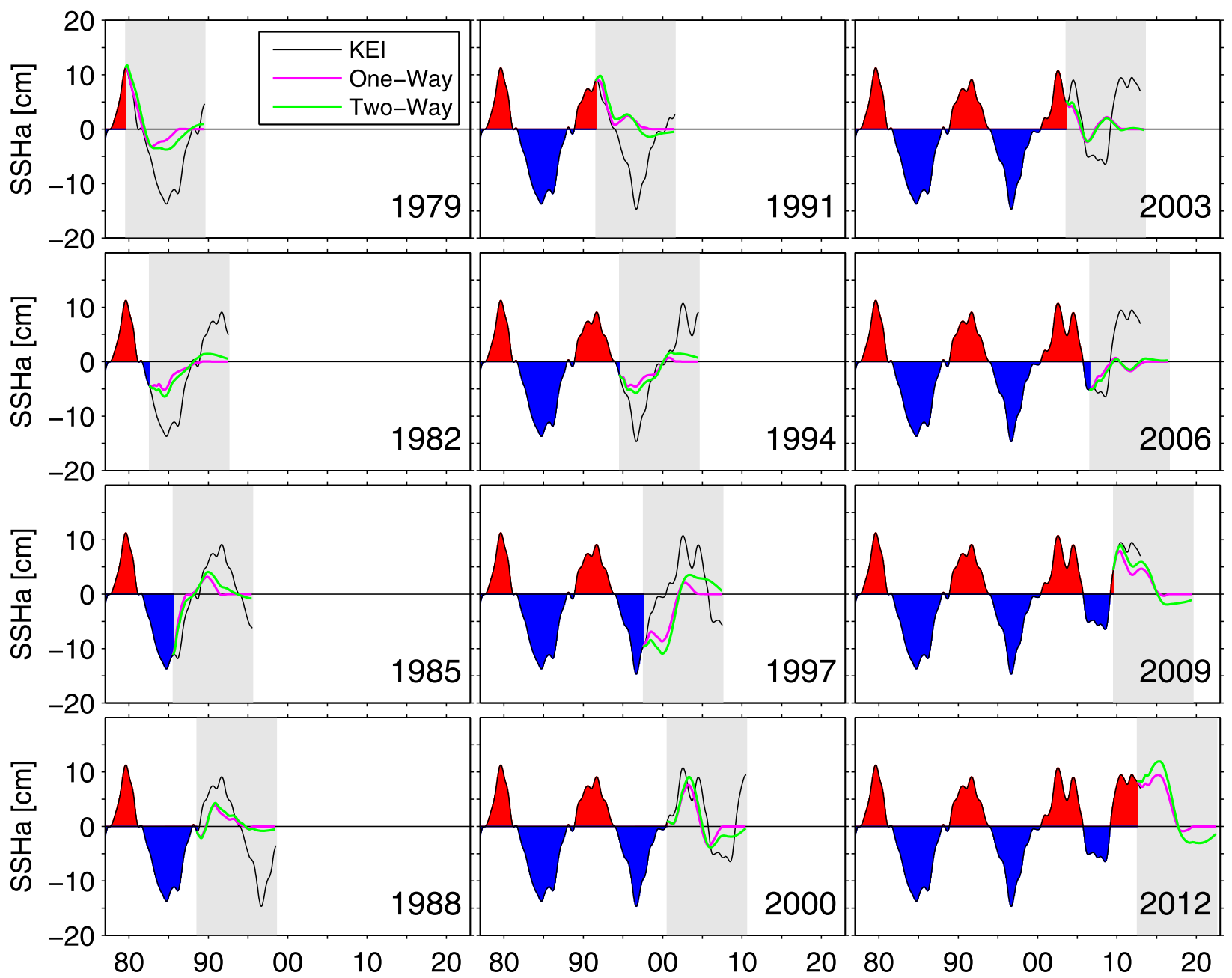

FIG. 8. Comparisons between the one-way (magenta lines) vs two-way (green lines) predictions of the KE index against the predictand KE index (black lines). The predicted period is shaded gray. Predictions start from July in the year indicated in the lower right corner of each individual panel.

We predict the subsequent KE index under 1) the Rossby wave adjustment (one way) and 2) the Rossby wave adjustment plus wind feedback (two way) scenarios.

In the one-way prediction, $w_{\mathrm{Ek}}=0$ and the initial SSH anomalies in the $31^{\circ}-36^{\circ} \mathrm{N}$ band are simply carried westward at the long baroclinic Rossby wave speed $c_{R}$ :

$$
\eta_{\text {one-way }}\left(x, \tau ; t_{o}\right)=\eta_{m}\left(x+c_{R} \tau, t_{o}\right),
$$

where both the initialization time $t_{o}$ and the lead time of prediction $\tau$ are used as time variables for $\eta_{\text {one-way. }}$ Once the SSH anomaly signals are obtained, the predicted KE index in this one-way case is given by

$I_{\text {one-way }}\left(\tau ; t_{o}\right)=\frac{1}{L} \int_{140^{\circ} \mathrm{E}}^{165^{\circ} \mathrm{E}} \eta_{\text {one-way }}\left(x^{\prime}, \tau ; t_{o}\right) d x^{\prime}$,

where $L$ is the length from $140^{\circ}$ to $165^{\circ} \mathrm{E}$. Using $c_{R}=$ $4.2 \mathrm{~cm} \mathrm{~s}^{-1}$ from the satellite altimeter measurements, we present in Fig. 8 examples of the $I_{\text {one-way }}\left(\tau, t_{o}\right)$ time series predicted for a $10-y r$ period (magenta lines). In each plot, the prediction is initiated from July of the year indicated in the plot. For comparison, the KE index $I_{\mathrm{KE}}(t)$, the predictand in this case, is shown in Fig. 8 by the black lines. With the exception of 1997, the $I_{\text {one-way }}$ time series appears to track $I_{\mathrm{KE}}(t)$ reasonably well, at least during the initial several years of the prediction.

Notice that the predictive skills in individual years can vary, depending on the amplitude of the initial SSH anomalies existing in the central and eastern North $\mathrm{Pa}$ cific Ocean (cf. Fig. 7). When the amplitude is small during, for example, the period when the wind-forced SSH signals change sign, the prediction of the KE index tends to have a lowered skill. By generating the $I_{\text {one-way }}(\tau ; t)$ time series with $t$ stepped forward monthly from 1977 to 2012, we can quantify the overall skill of the one-way prediction by 


$$
S_{\text {one-way }}(\tau)=1-\frac{\left\langle\left[I_{\text {one-way }}(\tau ; t)-I_{\mathrm{KE}}(t)\right]^{2}\right\rangle}{\left\langle I_{\mathrm{KE}}^{2}(t)\right\rangle},
$$

where angle brackets denote the ensemble average over the 1977-2012 period. The magenta line in Fig. 9 shows the predictive skill $S_{\text {one-way }}$ as a function of lead time $\tau$. Reflecting the importance of Rossby wave adjustment, $S_{\text {one-way }}$ greatly exceeds the skill of the damped persistence prediction ${ }^{1}$ (the black line in Fig. 9). At $\tau=3 \mathrm{yr}$, the Rossby wave adjustment prediction is able to explain $\sim 45 \%$ of the KE index variance. The one-way prediction skill, however, approaches very quickly that of the damped persistence prediction when $\tau>4 \mathrm{yr}$. This is so because after 4 years, most of the initial SSH signals will have reached $140^{\circ}-165^{\circ} \mathrm{E}$, depleting the information of the initial SSH signals (with $c_{R}=4.2 \mathrm{~cm} \mathrm{~s}^{-1}$, the SSH anomalies can propagate westward over a distance of $60^{\circ}$ longitude in a 4 -yr period).

In the Rossby wave adjustment plus wind feedback (two way) scenario, the predicted $\mathrm{SSH}$ values in the $\mathrm{KE}$ region of $140^{\circ}-165^{\circ} \mathrm{E}$ feedback to the Ekman pumping field (recall Fig. 6d) and can result in additional SSH changes along

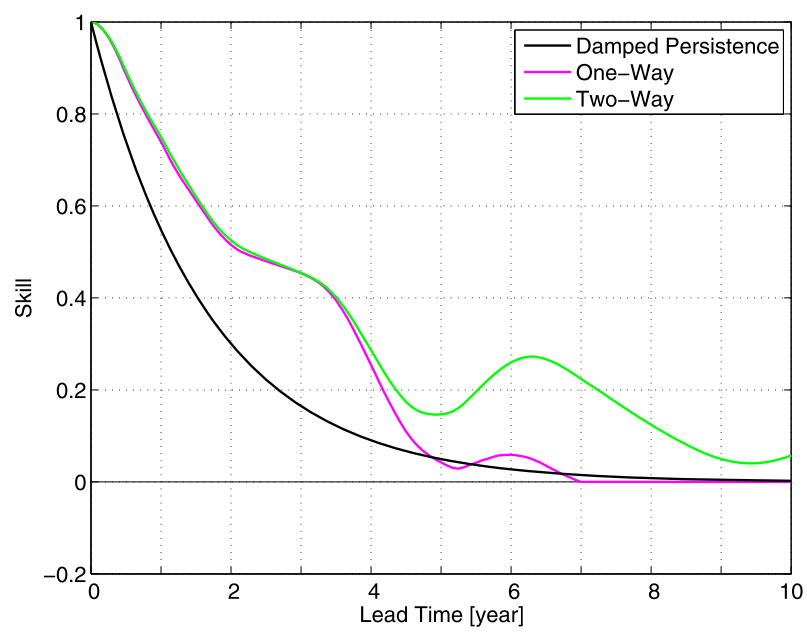

FIG. 9. Predictive skills of the KE index as a function of lead time based on the damped persistence (black line), the one-way wave adjustment (magenta line), and the two-way wave adjustment plus wind feedback (green line) scenarios.

the baroclinic Rossby wave paths. Using Eq. (3), we can express the two-way predicted SSH signals by

$$
\eta_{\text {two-way }}\left(x, \tau ; t_{o}\right)=\eta_{\text {one-way }}\left(x, \tau ; t_{o}\right)-\frac{g^{\prime}}{g} \int_{t_{o}}^{t_{o}+\tau} \bar{b}\left[x+c_{R}\left(t_{o}+\tau-t^{\prime}\right)\right] I_{\text {two-way }}\left(t^{\prime}-t_{o} ; t_{o}\right) d t^{\prime},
$$

where $\bar{b}(x)$ is the $b$ value meridionally averaged within the dashed box shown in Fig. $6 \mathrm{~d}$ and

$I_{\text {two-way }}\left(\tau ; t_{o}\right)=\frac{1}{L} \int_{140^{\circ} \mathrm{E}}^{165^{\circ} \mathrm{E}} \eta_{\text {two-way }}\left(x^{\prime}, \tau ; t_{o}\right) d x^{\prime}$

is the two-way predicted KE index. In the examples shown in Fig. 8, the two-way predictions are indicated by the green lines in the 10-yr lead-time windows. Compared to the magenta lines based on the one-way predictions, one can visually detect a better agreement between the green and black lines when the lead time exceeds several years.

To verify this visual comparison, we evaluate the skill of the two-way prediction using the formula similar to Eq. (6) and plot $S_{\text {two-way }}(\tau)$ in Fig. 9 as the green line. While the addition of the feedback Ekman pumping forcing contributes little to the KE index prediction with the lead time $<4 \mathrm{yr}$, it has a noticeable impact on forecast time longer than 4 yr. Specifically, inclusion

\footnotetext{
${ }^{1}$ The damped persistence prediction (Lorenz 1973) is given by $I_{d p}\left(\tau, t_{o}\right)=I_{\mathrm{KE}}\left(t_{o}\right) e^{-\alpha \tau}$, where $\alpha^{-1}$ is the autocorrelation time of the KE index time series and is estimated at $\sim 40$ months.
}

of the feedback Ekman pumping forcing can extend the $20 \%$ predictive skill to a lead time of $6-7 \mathrm{yr}$. Notice that the 4-yr lead time marks the transition when the initial SSH signals have reached the KE region and when the feedback wind-forced SSH signals from the central/eastern North Pacific Ocean start to reach the KE region.

\section{Summary}

Following the 1976-77 climate regime shift, the Kuroshio Extension system in the North Pacific has been observed to fluctuate between stable and unstable dynamic states on the decadal time scales. Manifested by the coherent changes in its stability, axis latitude, surface transport, and strength of the southern recirculation gyre, the dynamic state of the decadally varying $\mathrm{KE}$ system can be well represented by the SSH anomaly signals in the $31^{\circ}-36^{\circ} \mathrm{N}, 140^{\circ}-165^{\circ} \mathrm{E}$ region occupied by the time-mean KE jet and its southern recirculation gyre. Positive (negative) SSH anomalies in this region correspond to a stable (unstable) dynamic state and are defined by a positive (negative) KE index in this study. By combining the SSH anomaly signals from the satellite 
(a) Positive KE Index: Local High/Downstream Low P Anomalies

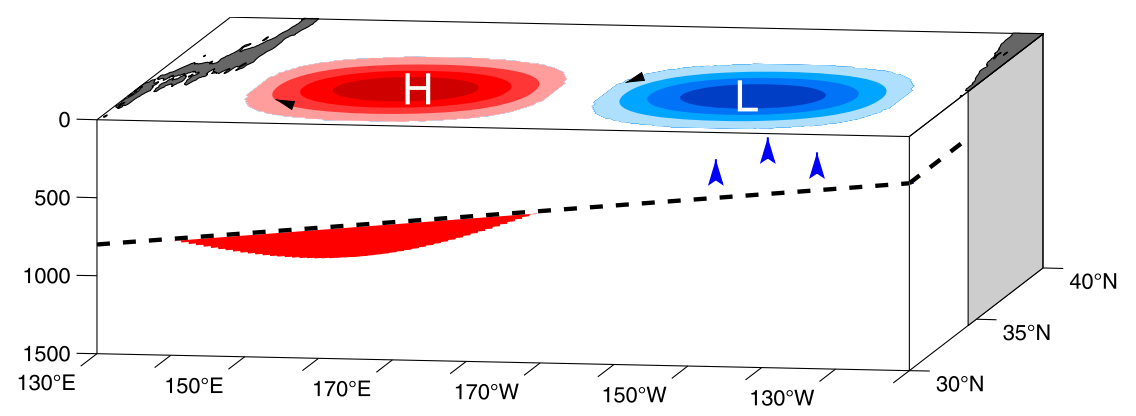

(b) Ekman Divergence in East; Westward Propagation of SSHa

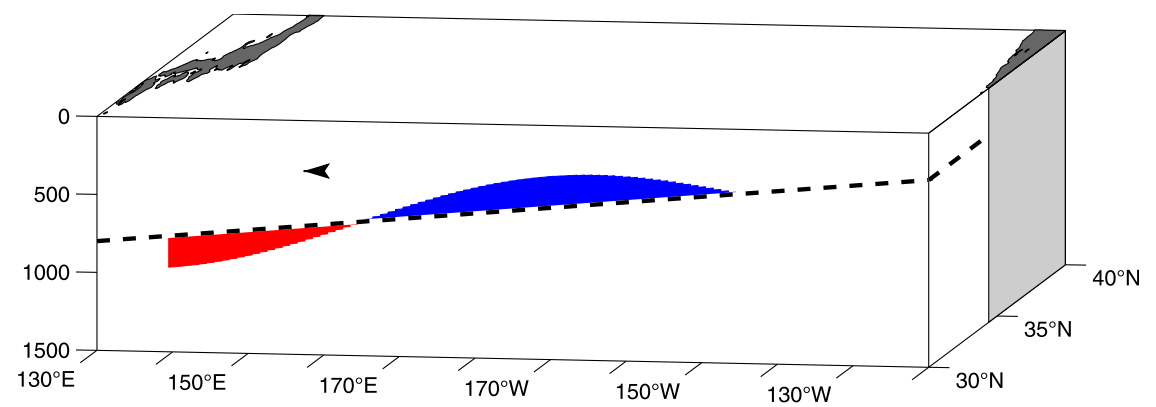

(c) Arrival of Negative SSHa Leads to Negative KEI, Reversing the Cycle

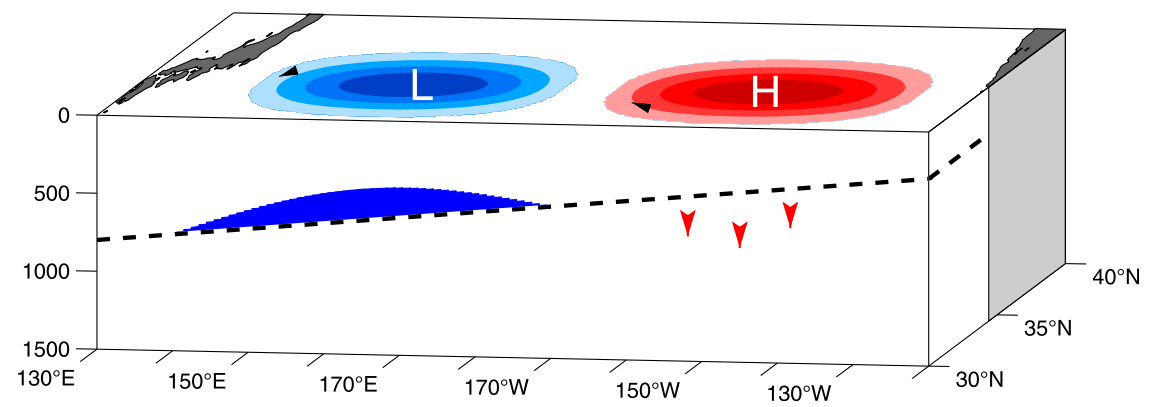

FIG. 10. Schematic of the air-sea coupled mode due to delayed negative feedback in the midlatitude North Pacific basin: $\mathrm{H}$ and L denote the surface pressure anomalies and dashed lines denote the permanent thermocline.

altimeter measurements and the eddy-resolving OFES hindcast simulation, we constructed the KE index for the period of 1977-2012.

Using the KE index thus constructed as the predictand, we explored its predictability by adopting two approaches. The first approach takes advantage of the facts that the SSH adjustment in the midlatitude ocean is via baroclinic Rossby waves and that the low-frequency wind forcing in the North Pacific has its center of action in the eastern part of the basin (Qiu 2003). With the phase speed $c_{R}=4.2 \mathrm{~cm} \mathrm{~s}^{-1}$ by the baroclinic Rossby waves along $31^{\circ}-36^{\circ} \mathrm{N}$, these facts result in a delayed SSH response at the ocean's western boundary where the $\mathrm{KE}$ is located. Compared to the damped persistence prediction, this "one way" prediction based on the wave adjustment process has much superior skill. Specifically, at the lead time of $4 \mathrm{yr}$, the one-way predicted KE index is able to account for $25 \%$ of the predictand's variance, whereas the explained variance is less than $10 \%$ with the damped persistence prediction. Skill values similar to our one-way prediction have been obtained by Schneider and Miller (2001) and Nonaka et al. (2012) in their predictability studies of the SST anomalies and the KE jet speed in the western North Pacific Ocean.

In contrast to the wave adjustment approach, our second approach of exploring the KE index prediction relies on the fact that the KE jet provides a significant source of heat and moisture for the extratropical storm 
tracks. By modifying the paths of the storm tracks, changes in the KE dynamic state alter the basin-scale wind stress pattern, which, in turn, can feedback to the SSH field in the KE region. By utilizing the lagged regression analyses to isolate the impact by the $\mathrm{KE}$ variability, we found that, when the KE index is in the positive phase, the enhanced KE surface transport and its northerly position work to generate warm SST and upward turbulent heat flux anomalies along the $35^{\circ}$ $40^{\circ} \mathrm{N}$ band across the North Pacific basin. These thermal forcings at the sea surface bring about the northward shift in both storm tracks and the large-scale Ekman pumping velocity field. Because the time-mean position of the $w_{\mathrm{Ek}}=0$ line in the North Pacific basin tilts northeastward from east of Japan to British Columbia, Canada, the Ekman pumping velocity induced by a stable KE system has positive anomalies in the eastern part of the $31^{\circ}-36^{\circ} \mathrm{N}$ band. As illustrated in Fig. 10a, these positive $w_{\mathrm{Ek}}$ anomalies generate negative SSH anomalies in the eastern Pacific basin through the local Ekman flux divergence. As these wind-induced negative $\mathrm{SSH}$ signals propagate westward into the KE region, they work to switch the phase of the KE dynamic state and result in a negative KE index (Figs. 10b,c). Once the dynamic state of the KE system becomes unstable, the sequence of processes with an opposite sign shown in Fig. 10 would take place. This delayed negative feedback mechanism in the midlatitude North Pacific increases the KE variability with a preferred period of $\sim 10 \mathrm{yr}$ (Qiu et al. 2007) and is the reason behind the improved predictive skills of the KE index by this "two way" approach beyond the 4-yr lead times.

The bottom-right panel in Fig. 8 presents the decadal prediction for the future KE index based on the observed SSH anomaly data of July 2012. While both oneway and two-way predictions indicate that the KE index will remain in a positive phase (i.e., an intensified and dynamically stable state) until 2016, the two-way prediction further suggests that the KE index will transition to a negative phase (a weakened and dynamically unstable state) beyond 2017. It will be interesting to verify these predictions in the coming years based on future satellite altimeter measurements and OFES hindcast simulations.

Acknowledgments. The OFES hindcast output used in this study was provided by Dr. Hideharu Sasaki of the Earth Simulator Center, the NCEP-NCAR reanalysis data by the National Centers for Environmental Prediction, the SST and surface turbulent flux data by the WHOI OAFlux project, and the merged satellite altimeter data by the CLS Space Oceanography Division as part of the Environment and Climate EU ENACT project. We acknowledge the support of NSF OCE-0926594 and NASA NNX13AE51G to BQ and SC and of Department of Energy Grant DE-SC0005111 and DE-SC006766 to NS. BT is supported by MEXT through Grant-in-Aid for Scientific Research in Innovative Areas 2205 and JSPS through KAKENHI 24540476 and 23340139.

\section{REFERENCES}

Alexander, M. A., I. Bladé, M. Newman, J. R. Lanzante, N.-C. Lau, and J. D. Scott, 2002: The atmospheric bridge: the influence of ENSO teleconnections on air-sea interaction over the global oceans. J. Climate, 15, 2205-2231.

Ceballos, L., E. Di Lorenzo, C. D. Hoyos, N. Schneider, and B. Taguchi, 2009: North Pacific Gyre Oscillation synchronizes climate variability in the eastern and western boundary current systems. J. Climate, 22, 5163-5174.

Deser, C., R. Thomas, and S. Peng, 2007: The transient atmospheric circulation response to North Atlantic SST and sea ice anomalies. J. Climate, 20, 4751-4767.

Ducet, N., P.-Y. Le Traon, and G. Reverdin, 2000: Global highresolution mapping of ocean circulation from TOPEX/Poseidon and ERS-1 and -2. J. Geophys. Res., 105, 19477-19498.

Frankignoul, C., and N. Sennéchael, 2007: Observed influence of North Pacific SST anomalies on the atmospheric circulation. J. Climate, 20, 592-606.

— A. Czaja, and B. L'Heveder, 1998: Air-sea feedback in the North Atlantic and surface boundary conditions for ocean models. J. Climate, 11, 2310-2324.

- N. Sennéchael, Y.-O. Kwon, and M. A. Alexander, 2011: Influence of the meridional shifts of the Kuroshio and the Oyashio Extensions on the atmospheric circulation. J. Climate, 24, 762-777.

Hoskins, B. J., and P. J. Valdes, 1990: On the existence of stormtracks. J. Atmos. Sci., 47, 1854-1864.

Joyce, T. M., Y.-O. Kwon, and L. Yu, 2009: On the relationship between synoptic wintertime atmospheric variability and path shifts in the Gulf Stream and the Kuroshio Extension. J. Climate, 22, 3177-3192.

Kelly, K. A., L. Thompson, W. Cheng, and E. J. Metzger, 2007: Evaluation of HYCOM in the Kuroshio Extension region using new metrics. J. Geophys. Res., 112, C01004, doi:10.1029/ 2006JC003614.

—, R. J. Small, R. M. Samelson, B. Qiu, T. M. Joyce, Y.-O. Kwon, and M. F. Cronin, 2010: Western boundary currents and frontal air-sea interaction: Gulf Stream and Kuroshio Extension. J. Climate, 23, 5644-5667.

Kistler, R., and Coauthors, 2001: The NCEP-NCAR 50-Year Reanalysis: Monthly means CD-ROM and documentation. Bull. Amer. Meteor. Soc., 82, 247-267.

Kwon, Y.-O., and C. Deser, 2007: North Pacific decadal variability in the Community Climate System Model version 2. J. Climate, 20, 2416-2433.

— spheric transient eddy heat fluxes and the Gulf Stream and Kuroshio-Oyashio Extension variability. J. Climate, 26, 98399859.

, M. A. Alenxader, N. A. Bond, C. Frankignoul, H. Nakamura, B. Qiu, and L. Thompson, 2010: Role of the Gulf Stream and Kuroshio-Oyashio systems in large-scale atmosphere-ocean interaction: A review. J. Climate, 23, 3249-3281. 
Latif, M., and T. P. Barnett, 1994: Causes of decadal climate variability over the North Pacific and North America. Science, 266, 634-637.

Lorenz, E. N., 1973: On the existence of extended range predictability. J. Appl. Meteor., 12, 543-546.

Mantua, N. J., S. R. Hare, Y. Zhang, J. M. Wallace, and R. C. Francis, 1997: A Pacific interdecadal climate oscillation with impacts on salmon production. Bull. Amer. Meteor. Soc., 78, 1069-1079.

Miller, A. J., D. R. Cayan, and W. B. White, 1998: A westwardintensified decadal change in the North Pacific thermocline and gyre-scale circulation. J. Climate, 11, 3112-3127.

—, F. Chai, S. Chiba, J. R. Moisan, and D. J. Neilson, 2004: Decadal-scale climate and ecosystem interactions in the North Pacific Ocean. J. Oceanogr., 60, 163-188.

Minobe, S., A. Kuwano-Yoshida, N. Komori, S.-P. Xie, and R. J. Small, 2008: Influence of the Gulf Stream on the troposphere. Nature, 452, 206-209.

Mizuno, K., and W. B. White, 1983: Annual and interannual variability in the Kuroshio Current system. J. Phys. Oceanogr., 13, 1847-1867.

Nakamura, H., T. Izumi, and T. Sampe, 2002: Interannual and decadal modulations recently observed in the Pacific storm track activity and East Asian winter monsoon. J. Climate, 15, 1855-1874.

—, T. Sampe, Y. Tanimoto, and A. Shimpo, 2004: Observed associations among storm tracks, jet streams and midlatitude oceanic fronts. Earth's Climate: The Ocean-Atmosphere Interaction, Geophys. Monogr., Vol. 147, Amer. Geophys. Union, 329-346.

Nishikawa, H., I. Yasuda, and S. Itoh, 2011: Impact of winter-tospring environmental variability along the Kuroshio jet on the recruitment of Japanese sardine. Fish. Oceanogr., 20, 570-582.

Nonaka, M., H. Nakamura, Y. Tanimoto, T. Kagimoto, and H. Dasaki, 2006: Decadal variability in the Kuroshio-Oyashio Extension simulated in an eddy-resolving OGCM. J. Climate, 19, 1970-1989.

—, H. Sasaki, B. Taguchi, and H. Nakamura, 2012: Potential predictability of interannual variability in the Kuroshio Extension jet speed in an eddy-resolving OGCM. J. Climate, 25, 3645-3652.

Noto, M., and I. Yasuda, 1999: Population decline of the Japanese sardine, Sardinops melanostictus, in relation to sea surface temperature in the Kuroshio Extension. Can. J. Fish. Aquat. Sci., 56, 973-983.

Oka, E., B. Qiu, S. Kouketsu, K. Uehara, and T. Suga, 2012: Decadal seesaw of the central and subtropical mode water formation associated with the Kuroshio Extension variability. J. Oceanogr., 68, 355-360.

Pierce, D. W., T. P. Barnett, N. Schneider, R. Saravanan, D. Dommenget, and M. Latif, 2001: The role of ocean dynamics in producing decadal climate variability in the North Pacific. Climate Dyn., 18, 51-70.

Qiu, B., 2000: Interannual variability of the Kuroshio Extension and its impact on the wintertime SST field. J. Phys. Oceanogr., 30, $1486-1502$.

_ 2002: Large-scale variability in the midlatitude subtropical and subpolar North Pacific Ocean: Observations and causes. J. Phys. Oceanogr., 32, 353-375.

- 2003: Kuroshio Extension variability and forcing of the Pacific decadal oscillations: Responses and potential feedback. J. Phys. Oceanogr., 33, 2465-2482.

- , and S. Chen, 2005: Variability of the Kuroshio Extension jet, recirculation gyre, and mesoscale eddies on decadal time scales. J. Phys. Oceanogr., 35, 2090-2103.
— , and — 2006: Decadal variability in the formation of the North Pacific Subtropical Mode Water: Oceanic versus atmospheric control. J. Phys. Oceanogr., 36, 1365-1380.

$\longrightarrow$, and — 2010: Eddy-mean flow interaction in the decadally modulating Kuroshio Extension system. Deep-Sea Res. II, 57, 1098-1110.

— , and — 2011: Effect of decadal Kuroshio Extension jet and eddy variability on the modification of North Pacific Intermediate Water. J. Phys. Oceanogr., 41, 503-515.

- N. Schneider, and S. Chen, 2007: Coupled decadal variability in the North Pacific: An observationally constrained idealized model. J. Climate, 20, 3602-3620.

Sasaki, H., M. Nonaka, Y. Masumoto, Y. Sasai, H. Uehara, and H. Sakuma, 2008: An eddy-resolving hindcast simulation of the quasi-global ocean from 1950 to 2003 on the Earth Simulator. High Resolution Numerical Modelling of the Atmosphere and Ocean, W. Ohfuchi and K. Hamilton, Eds., Springer, 157-185.

Sasaki, Y. N., S. Minobe, and N. Schneider, 2013: Decadal response of the Kuroshio Extension jet to Rossby waves: Observation and thin-jet theory. J. Phys. Oceanogr., 43, 442-456.

Schneider, N., and A. J. Miller, 2001: Predicting western North Pacific Ocean climate. J. Climate, 14, 3997-4002.

,,-- and D. W. Pierce, 2002: Anatomy of North Pacific decadal variability. J. Climate, 15, 586-605.

Seager, R., Y. Kushnir, N. H. Naik, M. A. Cane, and J. Miller, 2001: Wind-driven shifts in the latitude of the Kuroshio-Oyashio Extension and generation of SST anomalies on decadal timescales. J. Climate, 14, 4249-4265.

Taguchi, B., S.-P. Xie, N. Schneider, M. Nonaka, H. Sasaki, and Y. Sasai, 2007: Decadal variability of the Kuroshio Extension: Observations and an eddy-resolving model hindcast. $\mathrm{J}$. Climate, 20, 2357-2377.

— , H. Nakamura, M. Nonaka, and S. P. Xie, 2009: Influences of the Kuroshio/Oyashio Extensions on air-sea heat exchanges and storm-track activity as revealed in regional atmospheric model simulations for the 2003/04 cold season. J. Climate, 22, 6536-6560.

_ B. Biu, M. Nonaka, H. Sasaki, S.-P. Xie, and N. Schneider, 2010: Decadal variability of the Kuroshio Extension: Mesoscale eddies and recirculation. Ocean Dyn., 60, 673-691.

- , H. Nakamura, M. Nonaka, N. Komori, A. Kuwano-Yoshida, K. Takaya, and A. Goto, 2012: Seasonal evolutions of atmospheric response to decadal SST anomalies in the North Pacific subarctic frontal zone: Observations and a coupled model simulation. J. Climate, 25, 111-139.

Teague, W. J., M. J. Carron, and P. J. Hogan, 1990: A comparison between the Generalized Digital Environmental Model and Levitus climatologies. J. Geophys. Res., 95, 7167-7183.

Tokinaga, H., Y. Tanimoto, S.-P. Xie, T. Sampe, H. Tomita, and H. Ichikawa, 2009: Ocean frontal effects on the vertical development on clouds over the western North Pacific: In situ and satellite observations. J. Climate, 22, 4241-4260.

Trenberth, K. E., and J. W. Hurrell, 1994: Decadal atmosphereocean variations in the Pacific. Climate Dyn., 9, 303-319.

Vivier, F., K. A. Kelly, and L. A. Thompson, 2002: Heat budget in the Kuroshio Extension region: 1993-99. J. Phys. Oceanogr., 32, 3436-3454.

Wu, L., Z. Liu, R. Jacob, D. Lee, and Y. Zhong, 2003: Pacific decadal variability: The tropical Pacific mode and the North Pacific mode. J. Climate, 16, 1101-1120.

Yu, L., and R. A. Weller, 2007: Objectively analyzed air-sea heat fluxes for the global ice-free oceans (1981-2005). Bull. Amer. Meteor. Soc., 88, 527-539. 